\title{
REPRESENTAÇÕES SOBRE MEIO AMBIENTE DE ALUNOS DA EDUCAÇÃO BÁSICA DE PALMAS (TO)*
}

\section{Palmas (TO) Basic Education students' representations of the Environment}

\author{
Berenice Feitosa da Costa Aires ${ }^{1}$ \\ Rogério Pereira Bastos ${ }^{2}$
}

Resumo: As representações sociais sobre meio ambiente, de 791 alunos da Educação Básica de Palmas (TO), no Ensino Fundamental e Médio das redes privada, municipal e estadual, foram investigadas mediante análise de documentos e pesquisa de campo, utilizando-se a técnica de mapas mentais. A identificação dos elementos das representações de meio ambiente, apresentada pelos alunos, tomou por base a análise global dos desenhos de cada aluno das fases de Ensino Fundamental I e II, e Ensino Médio. Possivelmente, as origens das representações categorizadas estejam associadas, sobretudo, aos discursos dos professores e à própria vivência de cada aluno, à percepção que cada um tem do ambiente/lugar no qual reside

Palavras-chave: Meio ambiente. Representações sociais. Educação Básica.

\begin{abstract}
The social representations of the environment of 791 students of Basic Education for Palmas (TO) in elementary and high school networks both private, municipal and state were investigated by examining documents and field research, using the technique of mind mapping. The identification of elements of representations of the Environment, presented by the students was based on the overall analysis of each student's drawings of the stages of elementary school I and II, and High School. We considered that the origins of the representations are linked through categorization, especially the discourses of teachers and the very existence of each student, and the perception that each has of the environment / location in which they reside.
\end{abstract}

Keywords: Environment. Social representations. Basic Education.

\footnotetext{
*Elaborado com base em Aires (2010).

${ }^{1}$ Graduada em Geografia, doutoranda em Ciências Ambientais. Docente, curso de Geografia, campus de Porto Nacional, Universidade Federal do Tocantins. Palmas, TO, Brasil. < berenice@uft.edu.br>

${ }^{2}$ Graduado e doutor em Ciências Biológicas. Docente, Departamento de Ecologia/ICB, Universidade Federal de Goiás. Goiânia, GO, Brasil. < bastos@icb.ufg.br>
} 
Aires, B. F. C.; Bastos, R. P.

\section{Introdução}

O termo meio ambiente tornou-se comum no cotidiano dos brasileiros, sobretudo após a ECO-92 (ou RIO 92) - Conferência das Nações Unidas sobre Meio Ambiente e Desenvolvimento, realizada no Rio de Janeiro em 1992. Essa conferência, com seus desdobramentos, fomentou um uso frequente da expressão meio ambiente no nosso dia a dia, seja nas escolas, na comunidade ou nos veículos de comunicação social, tornando-a comum em nossas falas ${ }^{3}$. Geralmente, a expressão Meio Ambiente (MA) é adotada e usada como símbolo de natureza, ambientalismo, educação ambiental, ecologia, entre outros, não havendo um consenso geral sobre o significado deste termo, mesmo na comunidade científica. É certo, também, que o meio científico não ficou imune ao processo de popularização do termo MA. Podemos verificar isso em alguns discursos que querem congregar tudo em nome do ambiental, e o que é pior, com enfoque reducionista.

Pode-se observar, nas últimas disputas, que tem se intensificado uma evolução no conceito deste termo. Entretanto, parecendo cansativo e inútil discutir as concepções deste tema, tal discussão é pertinente, advindo da extrema necessidade, nos dias atuais, da interação entre desenvolvimento e MA, como nos fala Mendonça (2002, p. 43):

O debate acerca da concepção de meio ambiente parece por demais desnecessário, cansativo que o mesmo se tornou no seio da intelectualidade, mas a insistência na sua retomada neste momento advém da preocupação em evidenciar [...] a complexidade adquirida pelo termo nas duas últimas décadas, quando a mesma passa a envolver a sociedade, além de sua clássica base naturalista.

Ressaltamos que o termo MA ou ambiente tem uma longa história, marcada quase sempre por aspectos basicamente naturalistas, mas que, nas últimas décadas, tem se cercado, também, de aspectos sociais, inseridos no contexto de crise ecológica, de crise ambiental.

Assim, traçar caminhos para a compreensão do meio ambiente não é uma via simples, uma vez que diferentes concepções passam a incorporar o cotidiano. As representações expressas nos discursos, nas falas e nas práticas produzem diversos sentidos para o MA.

Neste sentido, alguns autores, como Leff (2001) e Moraes (2002), afirmam que, para um estudo do MA, é necessário conhecer e percorrer os fundamentos epistemológicos que são bases para o entendimento do mesmo e da temática ambiental. Para Moraes (2002), o avanço em qualquer área do conhecimento demanda um acompanhamento epistemológico constante. É através dele que estamos continuamente checando os enunciados gerados num campo de conhecimento, aferindo os instrumentos analíticos que temos e avaliando os resultados obtidos. Enfim, de acordo com este autor, é a epistemologia que permite agregar os novos conhecimentos que o desenvolvimento da pesquisa vai trazendo.

Moraes (2002) salienta ainda que é mais que adequado falar em bases epistemológi-

${ }^{3}$ Essa afirmativa foi comprovada pela pesquisa realizada por Samyra Crespo (2003) nos anos de 1992 e 2002. 
Representações sobre meio ambiente de alunos ...

cas sempre no plural, pois implica diferenciadas dimensões de trabalho. Assim, para uma investigação de ordem epistemológica, é preciso a evolução de três juízos. O primeiro deles é a defesa da necessária anterioridade do desenvolvimento disciplinar da pesquisa ambiental, ante o trabalho interdisciplinar, ou seja, primeiramente, é necessária uma base disciplinar. Somente a partir dos resultados obtidos na pesquisa disciplinar é que a interdisciplinar pode avançar. O segundo juízo refere-se à necessidade de uma reflexão metodológica ante a investigação empírica. Por fim, o terceiro juízo seria uma relação comunicativa em que os conceitos tivessem uma padronização mínima. Somado a estes três juízos, o autor acrescenta o fundamento ético para questionar a moral do trabalho científico.

Leff (2001) propõe uma epistemologia ambiental que seria um trajeto para chegar a saber o que é o ambiente, mas que essa epistemologia da ciência normal não é suficiente para aprender o ambiente. Assim, para pensar uma epistemologia ambiental, o faz inicialmente pela discussão da articulação entre as ciências na relação natureza-sociedade.

Essa articulação científica não pode ser pensada como uma fusão dos objetos teóricos das ciências - os quais constituem sua especificidade teórica e dos quais derivam seu efeito de conhecimento - mas como uma superdeterminação ou uma interdeterminação dos processos materiais dos quais as ciências produzem um efeito de conhecimento pela articulação de seus conceitos em seus respectivos campos teóricos. (LEFF, 2001, p. 31-32)

A partir dessa discussão relativa à articulação das ciências, o autor conduz à construção do saber ambiental especificamente pela racionalidade ambiental, numa contraposição à chamada racionalidade econômica, e declara, ainda, que o sentido ideológico da noção de ambiente ocorre na interface entre o conceito de MA e sua assimilação pelo sistema. Ainda, conforme Leff (2001)

O ambiente não é um objeto perdido no processo de diferenciação e especificação das ciências, nem um espaço reintegrável pelo intercâmbio interdisciplinar dos conhecimentos existentes. O ambiental é a falta insuperável do conhecimento, esse vazio onde se aninha o desejo de saber gerando uma tendência interminável para a completude das ciências, o equilíbrio ecológico e a justiça social. (LEFF, 2001, p. 18)

Desta forma, torna-se urgente e necessária a discussão dessas questões na escola, desde a mais tenra idade. Toda via, não em uma perspectiva mistificadora, ou como modismo, mas que possibilite, ao aluno, uma reavaliação crítica perante os problemas ambientais. Portanto, conhecer a representação dos alunos sobre as questões relativas ao Meio Ambiente poderá auxiliar o professor a entender como eles estão captando, interpretando, agindo em sua realidade próxima, já que essas representações são fundamentais na formação de opiniões e no estabelecimento de atitudes individuais e coletivas. No entanto, como são dinâmicas, é importante identificá-las, para que sejam trabalhadas tanto com alunos quanto nas relações escola-objetivos (BRASIL, 2001). 
Aires, B. F. C.; Bastos, R. P.

\section{Procedimentos metodológicos}

O estudo foi realizado entre janeiro e novembro de 2009, em 15 escolas das redes pública e privada da Educação Básica da cidade de Palmas (TO). Foi solicitado, ao grupo de estudantes, que representasse, de forma gráfica, o que eles entendem por MA, levando em consideração seu mundo vivido, o cotidiano, o lugar em que vivem e o concebido, ou seja, as ideias, as concepções que foram trabalhadas na escola pelos professores, as experiências trabalhadas em sala de aula a respeito do tema MA.

Os estudantes correspondem a 791 alunos da Educação Básica, assim distribuídos: 284 alunos do Ensino Fundamental I; 332 do Ensino Fundamental II e 175 alunos do Ensino Médio.

As representações de MA dos estudantes foram identificadas por meio de mapa mental, porque "pode ser considerado como um outro tipo de imagem que reflete o nível icônico da cognição e possui algum tipo de estruturação interna entre seus elementos formadores, remontando a uma alógica operacional" (DEL RIO, 1996 apud SOUZA; COELHO, s/d, p. 5). Além disso, porque, ao trabalharmos com as representações gráficas, em forma de mapa mental, estamos, de alguma forma, tornando a representação do conceito trabalhado mais próxima do sujeito pesquisado e, mesmo, qualificando essa representação, permitindo que se torne mais elaborada e também mais próxima do próprio mundo do sujeito.

A identificação dos elementos das representações de Meio Ambiente, por intermédio do mapa mental, apresentada pelos alunos da Educação Básica de Palmas - (TO), tomou por base a análise global dos desenhos de cada aluno, identificados por nível de ensino e escolas pertencentes à rede municipal, estadual e privada, conforme Tabelas 1, 2 e 3, respectivamente.

\section{Resultados e discussão}

Com base no critério quantitativo, elencamos numericamente os elementos que compõem os mapas mentais dos estudantes. Destacamos que essa análise quantitativa é importante na medida em que oferece elementos para identificarmos as raízes das representações.

O primeiro fato que destacamos nos mapas mentais analisados, da Rede Municipal de Ensino, foi o de que praticamente todos eles trazem elementos que caracterizam ambientes preservados. Outro fator que evidenciamos é que as formas de apresentação dos mapas se caracterizam pela forte presença de cores, o que consideramos que seja um mecanismo utilizado pelos estudantes para dar ênfase ao conteúdo da representação.

Outro destaque é dado aos elementos que fazem parte deste MA. Os elementos que aparecem com maior frequência são: vegetação, lago, lixeiras, casas - todos em alta proporcionalidade -, seguem serras e montanhas e ambientes urbanos. Um total de quarenta e três (43) mapas mentais trouxeram representação do lago, o que está associado à formação do Lago da Usina do Lajeado que margeia toda a cidade. Conforme demonstrado na Figura 1.

Ressaltamos que as representações gráficas que dizem respeito à presença da figura do lago constituem forte indicador da ligação afetiva dos estudantes com o ambiente e revelam, também, o modo como percebem o lugar onde residem. 
Representações sobre meio ambiente de alunos ...

Tabela 1. Quantitativo das representações gráficas dos estudantes da Rede Municipal.

\begin{tabular}{|c|c|c|c|c|c|c|c|c|c|c|}
\hline \multirow{2}{*}{ Elementos } & \multicolumn{3}{|c|}{$\begin{array}{c}\text { Escola M. } \\
\text { Vinicius } \\
\text { de Moraes } \\
\end{array}$} & & & \multicolumn{2}{|c|}{$\begin{array}{c}\text { Escola M. } \\
\text { Olga } \\
\text { Benário } \\
\end{array}$} & & \multicolumn{2}{|c|}{$\begin{array}{c}\text { Escola M. } \\
\text { Antônio G. } \\
\text { Carvalho } \\
\end{array}$} \\
\hline & & EF I & EF II & & & EF I & EF II & & EF I & EF II \\
\hline Vegetação & & 08 & 10 & & & 16 & 15 & & 15 & 10 \\
\hline Lago & & - & 05 & & & 02 & - & & 08 & - \\
\hline Seres humanos & & 04 & 01 & & & 05 & - & & - & - \\
\hline Serras e montanhas & & - & 01 & & & - & - & & - & - \\
\hline Casas & & - & 05 & & & 01 & - & & 05 & 01 \\
\hline Escola & & - & - & & & - & 04 & & 01 & - \\
\hline \multicolumn{11}{|l|}{ Outros elementos: } \\
\hline a) Lixeiras & & 16 & - & & & 04 & 07 & & 01 & - \\
\hline b) Ambientes urbanos & & - & - & & & 01 & 05 & & 02 & - \\
\hline c) Planeta Terra & & - & - & & & - & - & & - & - \\
\hline d) Nuvens & & - & 01 & & & - & & & - & - \\
\hline e) Cachoeiras & & - & - & & & - & - & & - & - \\
\hline f) Outros & & - & - & & & - & - & & - & 04 \\
\hline Total & & 28 & 23 & & & 29 & 31 & & 32 & 15 \\
\hline Total/ Mapa mental escola & & 51 & & & & & 0 & & & 17 \\
\hline \multirow{2}{*}{ Elementos } & \multicolumn{2}{|c|}{$\begin{array}{c}\text { Escola M. } \\
\text { Darcy } \\
\text { Ribeiro } \\
\end{array}$} & & \multicolumn{2}{|c|}{$\begin{array}{c}\text { Escola M. } \\
\text { Monteiro } \\
\text { Lobato }\end{array}$} & \multicolumn{3}{|c|}{ Total } & \multirow{2}{*}{\multicolumn{2}{|c|}{$\begin{array}{l}\text { Total } \\
\text { geral }\end{array}$}} \\
\hline & EF I & EF II & & EF I & EF II & & EF I & EF II & & \\
\hline Vegetação & 24 & 22 & & - & 06 & & 55 & 63 & & 106 \\
\hline Lago & - & - & & 18 & 10 & & 28 & 15 & & 43 \\
\hline Seres humanos & - & 02 & & - & - & & 09 & 03 & & 12 \\
\hline Serras e montanhas & - & - & & - & - & & - & 01 & & 01 \\
\hline Casas & 04 & 02 & & - & 07 & & 10 & 15 & & 25 \\
\hline Escola & - & - & & - & - & & 01 & 04 & & 05 \\
\hline \multicolumn{11}{|l|}{ Outros elementos: } \\
\hline a) Lixeiras & - & - & & 07 & - & & 28 & 07 & & 35 \\
\hline b) Ambientes urbanos & 02 & - & & - & 02 & & 05 & 07 & & 12 \\
\hline c) Planeta Terra & - & 02 & & - & - & & - & 02 & & 02 \\
\hline d) Nuvens & - & - & & 01 & - & & 01 & 01 & & 02 \\
\hline e) Cachoeiras & - & - & & 02 & - & & 02 & - & & 02 \\
\hline f) Outros & - & - & & - & - & & - & 04 & & 04 \\
\hline Total & 30 & 28 & & 28 & 25 & & & & & \\
\hline Total/ Mapa mental escola & \multicolumn{3}{|c|}{58} & \multicolumn{2}{|c|}{53} & & 139 & 132 & & 249 \\
\hline
\end{tabular}

Fonte: Dados da pesquisa (2009).

Outro destaque desta análise refere-se à presença de lixeiras, que aparecem em 35 mapas mentais (Figuras 2 e 3). Associamos estas representações a uma prática comum na sala de aula e que também foi retratada pelos professores nos questionários, onde a maioria deles assinalou o tema lixo como conteúdo curricular dos temas transversais. 


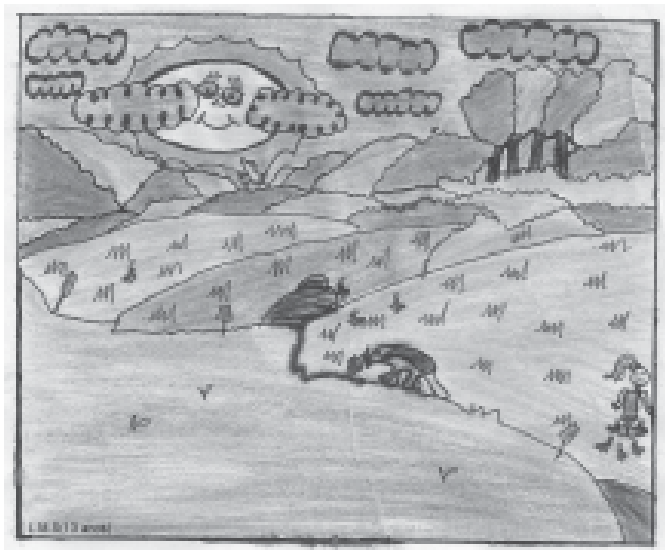

Figura 1. Exemplo de mapa mental representando o lago.

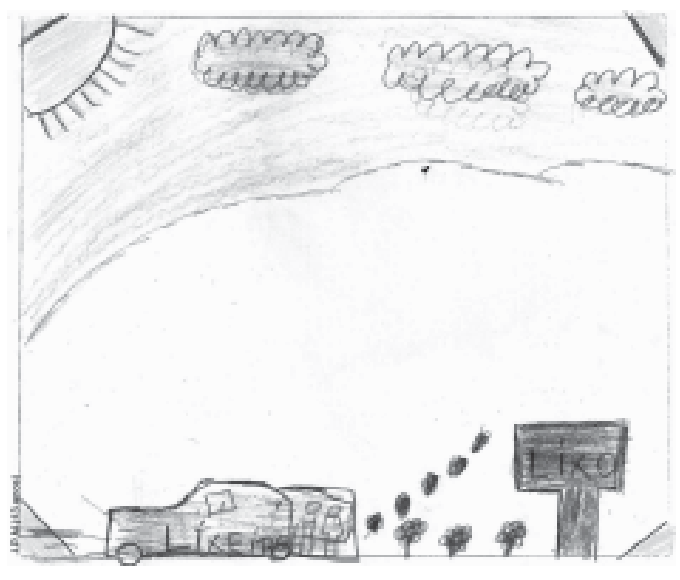

Figura 2. Exemplo de mapa mental representando o lixo.

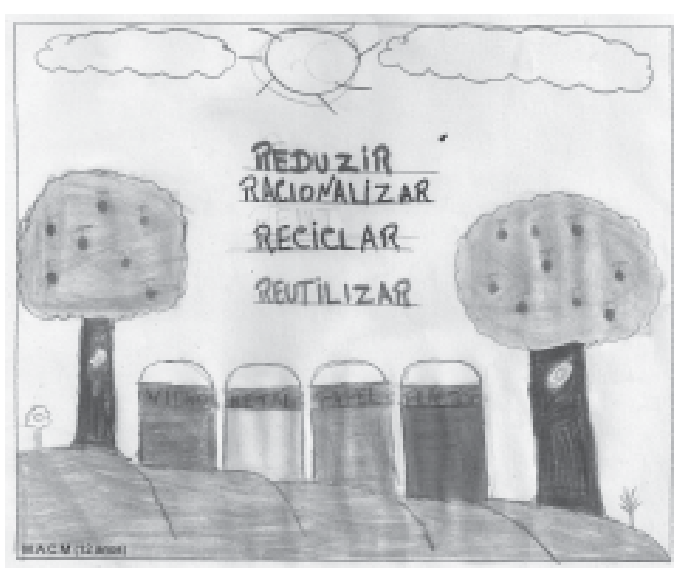

Figura 3. Exemplo de mapa mental representando o lixo.

Em diversos mapas mentais, a figura da casa foi marcante e assume uma dimensão importante na análise. Para Bachelard (2003 p. 23), ao tratar do universo da casa, assume que “a casa é o nosso canto do mundo. Ela é, como se amiúde, o nosso primeiro universo. É um verdadeiro cosmos. Um cosmos em toda acepção do termo". Nos mapas mentais, a casa aparece com maior frequência nas representações de estudantes do Ensino Fundamental I, destacando-se a presença de vegetação e o lago em torno. Esses fatores são indicativos da idéia de aconchego, de interação com o lugar.

Com relação ao elemento humano presente nas representações gráficas, chamou atenção o fato de que ele aparece em 12 mapas mentais. Notamos, nos mapas, que os elementos naturais são fortemente caracterizados e o ser humano está rodeado pelos elementos da natureza. 
Representações sobre meio ambiente de alunos ...

Os mapas a seguir, das Figuras 4 e 5, revelam que a representação de MA presente está associada à relação entre o eu, a sociedade e a comunidade, tendo a escola como elo neste contexto. Essa representação destaca a prática social e as relações humanas, ou seja, a interação social entre escola/comunidade como sendo MA.

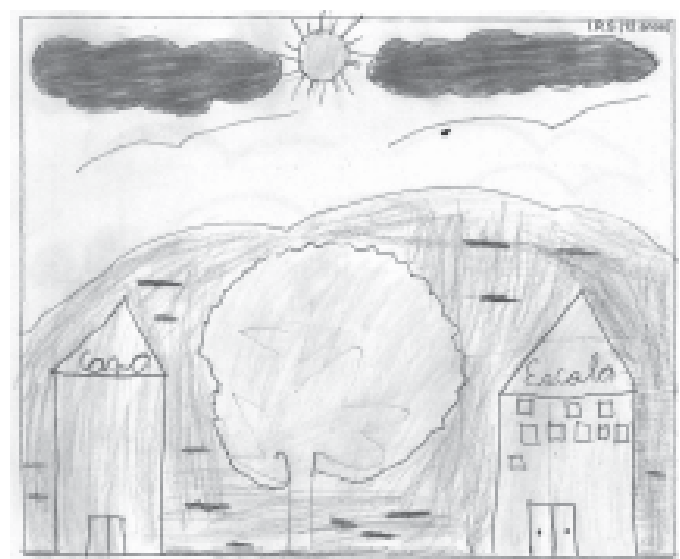

Figura 4. Mapa mental.

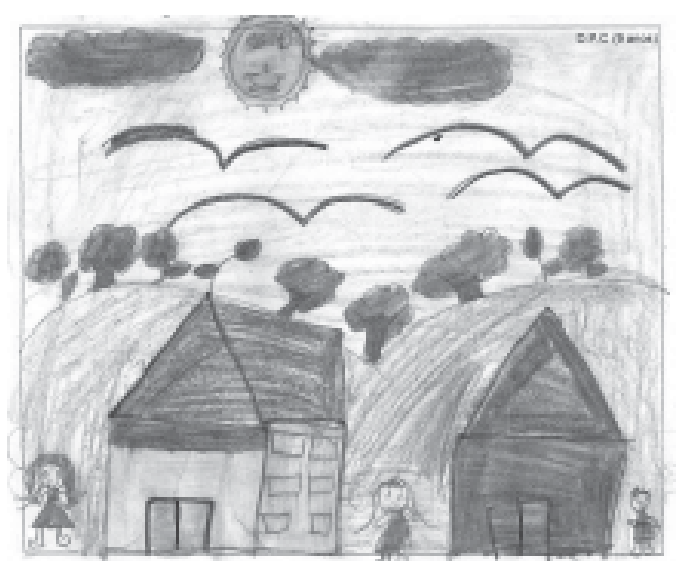

Figura 5. Mapa mental.

Observamos que as representações nestes mapas mentais se inserem na dimensão complexo-interativa, na medida em que a representação gráfica pressupõe uma contribuição, uma relação conjunta entre: a comunidade, a escola, o eu e o MA.

A partir dos dados levantados nas representações gráficas dos estudantes da Rede Municipal de Ensino, nos chamou atenção a presença mínima de elementos urbanos, e de ambientes construídos pela ação humana, deixando evidente compreensão de MA como sinônimo de natureza/vida. Observamos que essas representações focam a dimensão significativa. Esse fato está relacionado tanto ao ensino quanto ao discurso dos professores.

Conforme Tabela 2, os elementos que compõem os mapas mentais dos estudantes da Rede Estadual de Ensino estão demonstrados a seguir.

Evidenciamos um enorme quantitativo de mapas mentais que trazem elementos que caracterizam ambientes preservados, também evidenciado na Rede Municipal de Ensino. Outro destaque é o número elevado de representações de serras/montanhas/rios/lagos e cachoeiras. Esse quantitativo está expresso na seguinte proporção: 22 mapas mentais foram representados por alunos do Ensino Fundamental I, 48 por alunos do Ensino Fundamental II, sendo apenas 17 do Ensino Médio.

No caso específico do Ensino Fundamental I, II, esse quantitativo de setenta mapas mentais caracteriza os elementos serras/montanhas/lagos/cachoeiras, conforme Figuras 6 e 7. Ressaltamos que estes elementos estão associados às formações do relevo em que se encontra a cidade. Evidenciamos que o lugar em que se dá a pesquisa, conforme demonstrado na Figura 6, está localizado em uma região fortemente caracterizada por esses elementos. A referência repetitiva destes elementos constitui um forte indicador da ligação afetiva dos estudantes com o ambiente, e revela, também, o modo de perceber esse lugar. 
Aires, B. F. C.; Bastos, R. P.

Tabela 2. Quantitativo das representações gráficas dos estudantes da Rede Estadual.

\begin{tabular}{|c|c|c|c|c|c|c|c|c|}
\hline \multirow{2}{*}{ Elementos } & \multicolumn{2}{|c|}{$\begin{array}{l}\text { Colégio E. } \\
\text { São José }\end{array}$} & \multicolumn{2}{|c|}{$\begin{array}{l}\text { Colégio E. } \\
\text { Madre Belém }\end{array}$} & \multicolumn{2}{|c|}{$\begin{array}{l}\text { Colégio E. } \\
\text { Dom Alano }\end{array}$} & \multicolumn{2}{|c|}{$\begin{array}{l}\text { Centro de Ensino } \\
\text { Médio de Palmas }\end{array}$} \\
\hline & EF I & EF II & EF II & $\begin{array}{l}\text { Ensino } \\
\text { Médio }\end{array}$ & EF I & EF II & $1^{\circ}$ ano & $3^{\circ}$ ano \\
\hline Vegetação & & 12 & & & 19 & 08 & & \\
\hline Rio & & & & 04 & & & & \\
\hline Serras e montanhas/lago & 14 & 19 & 10 & & 08 & 19 & 01 & 05 \\
\hline Casas & & & & 01 & 03 & 06 & 05 & 04 \\
\hline Árvores & 13 & & 25 & 20 & 05 & & 20 & 09 \\
\hline Outros elementos: & & & & & & & 02 & 02 \\
\hline a) Lixeiras & & & & & & 03 & & 08 \\
\hline b) Ambientes urbanos & 02 & & & 02 & & 02 & 03 & 02 \\
\hline c) Planeta Terra & 01 & 01 & 01 & & 01 & & 04 & 05 \\
\hline f) Outros & 30 & 32 & 36 & 27 & 36 & & 35 & 35 \\
\hline Total & & & & & & 38 & & \\
\hline Total/Mapa mental escola & & 2 & & 63 & & 4 & & 70 \\
\hline \multirow{2}{*}{ Elementos } & \multicolumn{3}{|c|}{$\begin{array}{c}\text { Centro de Ensino } \\
\text { Tiradentes }\end{array}$} & Total & \multicolumn{2}{|l|}{ Total } & Total & Total \\
\hline & \multicolumn{2}{|c|}{$1^{\circ}$ ano } & $3^{\circ}$ ano & EF I & \multicolumn{2}{|c|}{ EF II } & $\begin{array}{l}\text { Ensino } \\
\text { Médio }\end{array}$ & Geral \\
\hline Vegetação & & & & 19 & 20 & & & 39 \\
\hline Rio & & & & & & & 04 & 04 \\
\hline Serras e montanhas/lago & & 04 & 07 & 22 & 48 & & 17 & 87 \\
\hline Casas & & 07 & 04 & 03 & 06 & & 21 & 30 \\
\hline Árvores & & 05 & 02 & 18 & 25 & & 56 & 99 \\
\hline Outros elementos: & & 02 & 05 & & & & & \\
\hline a) Lixeiras & & & & & 03 & & 11 & 14 \\
\hline b) Ambientes urbanos & & & & & 02 & & 08 & 10 \\
\hline c) Planeta Terra & & 03 & 03 & 02 & & & 07 & 09 \\
\hline $\begin{array}{l}\text { f) Outros } \\
\text { Total }\end{array}$ & & 21 & 21 & 02 & 02 & & 15 & 19 \\
\hline Total/Mapa mental escola & & & 42 & 66 & 106 & & 139 & 311 \\
\hline
\end{tabular}

Fonte: Dados da pesquisa (2009).

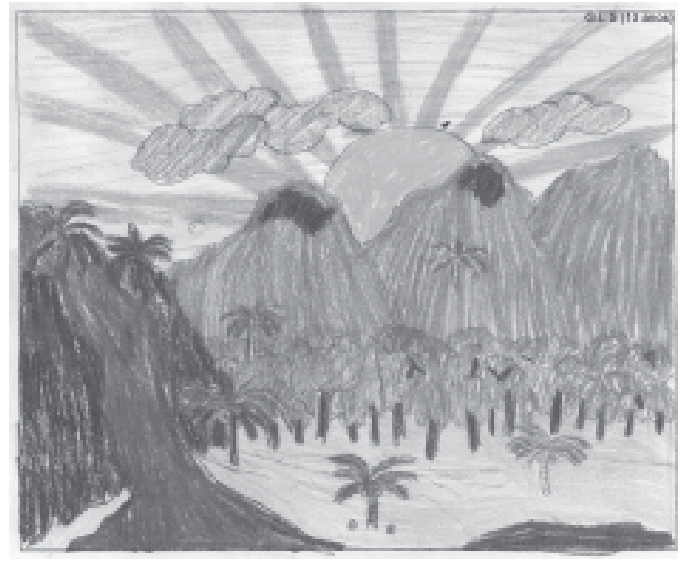

Figura 6. Mapa mental.

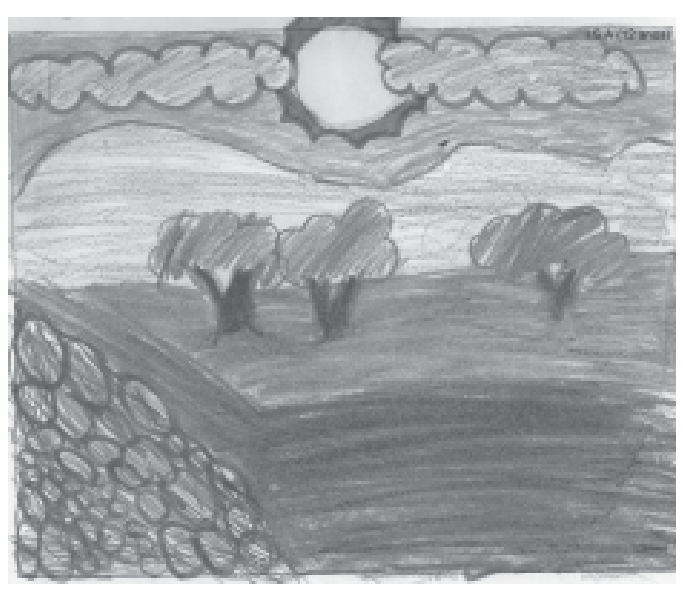

Figura 7. Mapa mental. 
Representações sobre meio ambiente de alunos ...

Em relação ao Ensino Médio, o destaque é o elevado número de mapas mentais que trazem como elemento o desenho de árvores, sendo um total de 56, o que caracteriza ambientes preservados. Outro destaque é o número de mapas mentais em que aparece o elemento casa, num total de 21 representações, o que, segundo Bachelard (2003, p. 23), ao tratar do universo casa, assume, também, que "a casa é o nosso canto do mundo". Nos mapas mentais, a casa aparece, com maior frequência, nas representações dos estudantes cuja faixa etária é entre 15 e 16 anos. Destacamos que esse fator revela que a representação de MA presente está associada à relação entre o eu, a sociedade e a comunidade, tendo a escola como elo neste contexto. Essas representações destacam a prática social e as relações humanas, ou seja, a interação social entre escola/comunidade como sendo MA.

Outro fator nos chamou atenção no que diz respeito ao elemento humano totalmente inexistente nas representações gráficas dos estudantes da Rede Estadual de Ensino. O que vem confirmar, mais uma vez, a visão de MA como sinônimo de natureza/vida, é uma visão de EA focada no discurso do professor que ainda trabalha com uma vertente de EA conservacionista.

Na Tabela 3, apontamos os elementos que compõem as representações gráficas dos estudantes da Rede Privada de Ensino.

Ao analisarmos os mapas mentais dos estudantes da Rede Privada de Ensino, destacamos que praticamente todos eles trazem elementos que caracterizam ambientes preservados. Os elementos que aparecem com maior frequência são: serras/montanhas/lagos/rios, vegetação, árvores, num total de 172 elementos.

Em relação às representações gráficas que dizem respeito à presença dos elementos serras/montanhas/lagos/rios, estas representam a percepção que os alunos possuem do lugar, uma vez que o lugar em que se realizou a pesquisa é uma região fortemente caracterizada por esses elementos. O mapa mental da Figura 8 é indicativo dessa representação.

Outro fator de destaque é para as representações gráficas dos alunos do Ensino Fundamental I e II, o elevado número de elementos (árvores e vegetação) que caracterizam os ambientes preservados, que pode estar relacionado aos discursos dos professores e à prática de uma EA focada numa vertente conservacionista, em que ocorre a transmissão de conceitos específicos e naturais. A representação gráfica da Figura 9 é uma demonstração desse fator.

Já com relação ao Ensino Médio, queremos destacar a presença, nas representações gráficas dos estudantes, do elemento que caracteriza ambientes urbanos construídos pela ação humana (conforme demonstrado na Figura 10). Esse fator pode estar relacionado tanto ao ensino e discurso do professor quanto ao próprio nível de desenvolvimento cognitivo dos estudantes, bem como ao nível socioeconômico, pois esses estudantes pertencem uma classe social com maior poder aquisitivo, portanto, com maior acesso às informações divulgadas pela mídia e outros conhecimentos.

Pudemos observar que os estudantes da Educação Básica de Palmas que fizeram parte da nossa investigação reproduzem os significados próprios do grupo; e mesmo sendo sempre únicos na criação de suas ideias, ao interagirem com o grupo, ao participarem de um processo educativo, os estudantes formam, então, sua representação a partir do intra e interpessoal. Assim, ao interagirem com o grupo e participarem de um processo educativo, os estudantes incorporam os conhecimentos do vivido, do percebido e do concebido. 
Aires, B. F. C.; Bastos, R. P.

Tabela 3. Quantitativo das representações gráficas dos estudantes da Rede Privada.

\begin{tabular}{|c|c|c|c|c|c|c|c|c|c|}
\hline \multirow{2}{*}{ Elementos } & \multicolumn{2}{|c|}{$\begin{array}{c}\text { Colégio São } \\
\text { Francisco } \\
\text { de Assis }\end{array}$} & & \multicolumn{2}{|c|}{$\begin{array}{l}\text { Colégio } \\
\text { Einstein }\end{array}$} & \multicolumn{2}{|c|}{$\begin{array}{c}\text { Colégio Ulbra } \\
\text { de Palmas }\end{array}$} & \multicolumn{2}{|c|}{$\begin{array}{c}\text { Colégio Objetivo } \\
\text { de Palmas }\end{array}$} \\
\hline & EF I & EF II & & EF II & EF II & EF II & $\begin{array}{l}1^{\circ} \text { ano } \\
\text { do EM }\end{array}$ & EF II & $\begin{array}{l}1^{\circ} \text { ano } \\
\text { do EM }\end{array}$ \\
\hline Vegetação & 07 & 11 & & 07 & & 06 & 05 & 05 & 05 \\
\hline Seres humanos & & & & 01 & & & 02 & 02 & \\
\hline Serras e montanhas/rios & 06 & 08 & & 04 & 06 & 09 & 17 & 09 & 13 \\
\hline Casas & 01 & & & 01 & 01 & & & 02 & \\
\hline Árvores & 02 & & & & 05 & 08 & & 02 & \\
\hline \multicolumn{10}{|l|}{ Outros elementos } \\
\hline a) Lixeiras & & & & 01 & 01 & & 02 & & \\
\hline b) Ambientes urbanos & & & & 03 & & 02 & 04 & 02 & 09 \\
\hline c) Planeta Terra & & & & & & & & 06 & 02 \\
\hline e) Cachoeiras & & & & & & & & & 01 \\
\hline f) Outros & & & & & 04 & & & 01 & \\
\hline Total & 16 & 19 & & 17 & 17 & 25 & 30 & 29 & 30 \\
\hline Total/Mapa mental escola & & 35 & & & 34 & & 55 & & 58 \\
\hline \multirow{2}{*}{ Elementos } & \multicolumn{4}{|c|}{$\begin{array}{c}\text { Escola Madre } \\
\text { Clélia } \\
\end{array}$} & Total & \multicolumn{2}{|c|}{ Total } & Total & Total \\
\hline & \multicolumn{2}{|r|}{ EF I } & EF II & & EF I & \multicolumn{2}{|c|}{ EF II } & $\begin{array}{l}\text { Ensino } \\
\text { Médio }\end{array}$ & Geral \\
\hline Vegetação & & & & & 14 & \multicolumn{2}{|c|}{22} & 10 & 46 \\
\hline Seres humanos & & & & & 01 & \multicolumn{2}{|c|}{02} & 02 & 05 \\
\hline Serras e montanhas/rios & & 07 & 12 & & 17 & \multicolumn{2}{|c|}{44} & 30 & 91 \\
\hline Casas & & & & & 02 & \multicolumn{2}{|c|}{03} & & 05 \\
\hline Árvores & & 18 & & & 20 & 15 & & & 35 \\
\hline \multicolumn{10}{|l|}{ Outros elementos } \\
\hline a) Lixeiras & & & 03 & & 01 & \multicolumn{2}{|c|}{04} & 02 & 07 \\
\hline b) Ambientes urbanos & & & & & 03 & \multicolumn{2}{|c|}{04} & 13 & 20 \\
\hline c) Planeta Terra & & 05 & 02 & & 05 & \multicolumn{2}{|c|}{08} & 02 & 15 \\
\hline e) Cachoeiras & & & & & & & & 01 & 01 \\
\hline f) Outros & & & 01 & & & \multicolumn{2}{|c|}{06} & & 06 \\
\hline Total & & 30 & 18 & & & & & & \\
\hline Total/Mapa mental escola & \multicolumn{4}{|c|}{48} & 63 & \multicolumn{2}{|c|}{108} & 60 & 231 \\
\hline
\end{tabular}

Fonte: Dados da pesquisa (2009).

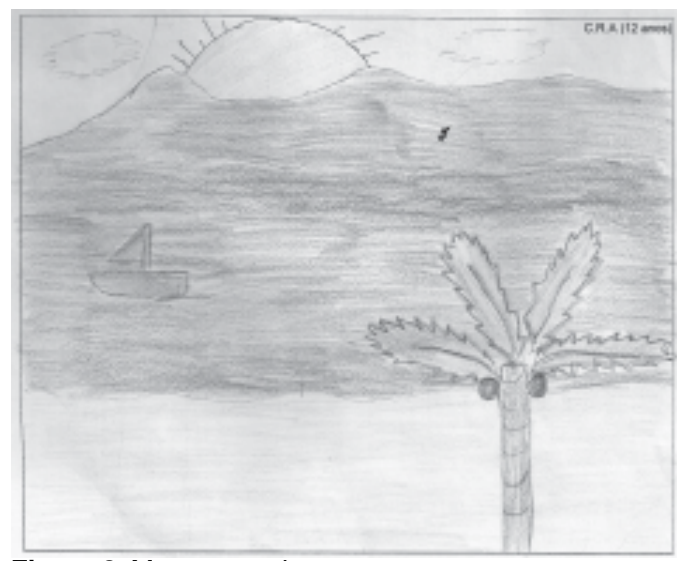

Figura 8. Mapa mental. 


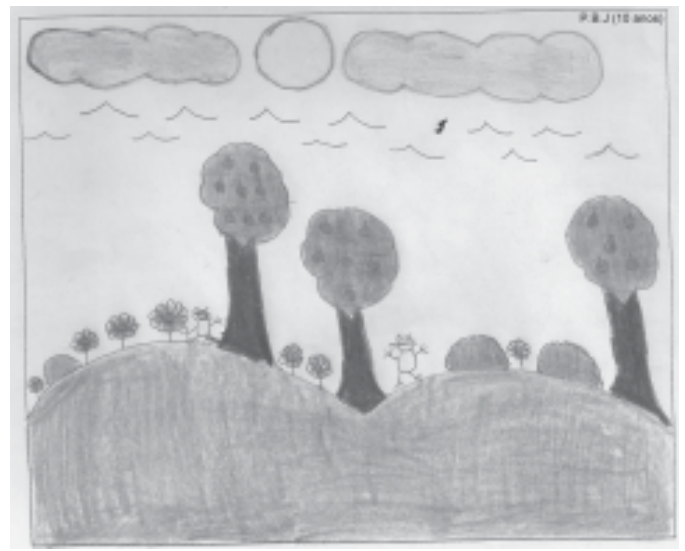

Figura 9. Mapa mental.

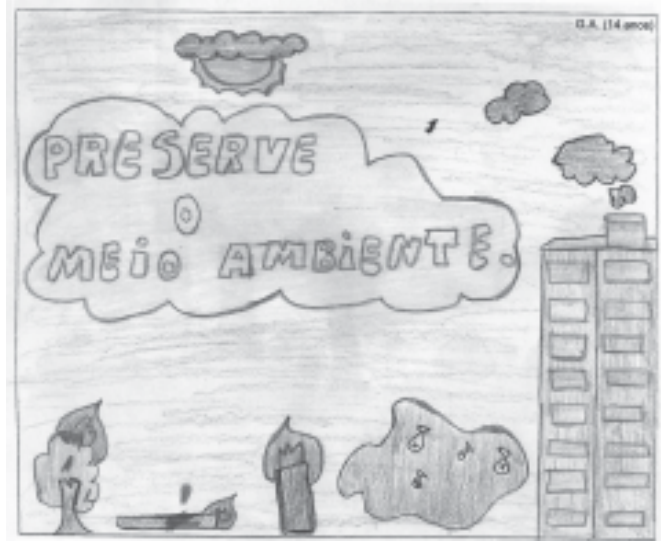

Figura 10. Mapa mental.

Por meio dos mapas mentais, pudemos, então, desvelar as dimensões do vivido, do percebido e do concebido na representação do MA dos estudantes, onde está inserida tanto a dimensão significativa quanto a dimensão interativa.

\section{Considerações finais}

Por meio da técnica de mapa mental utilizada, observamos uma diferença considerável em termos de liberdade de expressão dos sujeitos investigados. Esta constatação nos encoraja a citar alguns cuidados que, segundo nosso julgamento, podem ser levados em consideração e avaliados no que diz respeito às investigações em representações sociais junto a estudantes da Educação Básica: a utilidade exclusiva de questionários para coleta de dados pode se apresentar como "fator limitante" para expressão, em vista das dificuldades apresentadas por crianças daquela faixa etária com relação à escrita.

Ao analisar os mapas mentais dos estudantes, temos claro que estes são representações que, inicialmente, têm por base a percepção. Portanto, ao buscarmos compreender as representações gráficas de MA dos estudantes, devemos levar em conta, primeiramente, o ato perceptivo que os estudantes têm de MA, e que foi construído durante seu contato com o ambiente em que vivem.

Desta forma, os elementos que apareceram com maior frequência foram: a vegetação, seguida pelos corpos de água (lagos, cachoeiras) e representações da fauna - o que constitui um forte indicador da ligação afetiva dos estudantes com o ambiente, e revela, também, o modo de perceberem esse lugar. Evidenciamos que o lugar em que se dá a pesquisa está localizado em uma região fortemente caracterizada por elementos da vegetação, rios e lagos.

No geral, a representação preservacionista é aquela que predomina entre os alunos da Educação Básica de Palmas, ou seja, a compreensão de MA como sinônimo de natureza/vida. Essa representação está relacionada às práticas pedagógicas de EA dos professores que está 
Aires, B. F. C.; Bastos, R. P.

focada numa vertente de EA conservacionista, em que ocorre a transmissão de conceitos específicos e naturais.

Nesse sentido, é importante ressaltar que, perante a complexidade das questões ambientais, as práticas educativas não podem deixar de buscar a aproximação com ideias, crenças, valores e atitudes dos envolvidos no processo educativo. Assim sendo, a escola deve incentivar um trabalho coletivo, capaz de desencadear reflexões e ações que levem o professor a compreender as questões ambientais para além de suas dimensões biológicas, refletindo sobre aspectos políticos, socioeconômicos e éticos, em um processo contínuo de formação do educador ambiental.

\section{Referências}

AIRES, B. F. C. Educação Ambiental no contexto de Palmas "Capital Ecológica”. 2010. 143f. Tese (Doutorado) - Programa de Ciências Ambientais, Universidade Federal de Goiás, Goiânia, 2010.

AMORIM FILHO, O. B.; ABREU, J. F. Imagem, representação e geopolítica. In: MENDONÇA, F. S.; KOSEL, S. (Orgs.). Elementos de epistemologia da geografia contemporânea. Curitiba: Ed. UFPR, 2002. p. 233-251.

BACHELARD, G. A poética do espaço. São Paulo: Martins Fontes, 2003.

BRASIL. Ministério da Educação e do Desporto. Secretaria de Educação Fundamental. Parâmetros curriculares nacionais: meio ambiente e saúde. 3. ed. Brasília: MEC/SEF, 2001. v. 9.

CRESPO, S. Uma visão sobre a evolução da consciência ambiental no Brasil nos anos 1990. In: TRIGUEIRO, A. (Coord.). Meio ambiente no século XXI. Rio de Janeiro: Sextante, 2003. p. 59-73.

LEFF, E. Epistemologia ambiental. São Paulo: Cortez, 2001.

MENDONÇA, F. Geografia e meio ambiente. São Paulo: Contexto, 2002a.

MORAES, A. C. R. Fundamentos epistemológicos para o estudo do meio ambiente. In: . Meio ambiente e ciências humanas. São Paulo: Hucitec, 2002. p. 17-158.

SOUZA, L. C. T.; COELHO, S. S. Aplicação metodológica de mapas mentais em estudos da percepção ambiental com ênfase no planejamento turístico: uma proposta de minicurso. Curitiba, s/d.

Artigo recebido em maio de 2010 e aceito em dezembro de 2010. 